\title{
CATASTROPHIC HOUSEHOLD HEALTH EXPENDITURES AND ITS POVERTY IMPACT (A CASE STUDY OF RURAL AND URBAN AREA OF EASTERN CHITWAN) \\ Krishna Giri*
}

\begin{abstract}
The principle of "health as a fundamental right of the people" is enshrined in the constitution of Nepal 2072 which has guided the state's obligation towards good health for all Nepali people. In order to ensure this constitutional obligation there is a need to provide equitable health services that factor in differences in geographical area, gender, caste and economic conditions. The study describes the field study on the catastrophic health expenditure and its impact on poverty in Ratnanagar municipality and shaktikhor village of eastern chitwan. The people in the study area are highly affected by catastrophic health expenditure. Catastrophic health expenditure is experienced by all socio- economic groups but severe impoverishment impact is experienced by poor. The impact of out-of pocket payments for health care can become catastrophic over time and can significantly affect the living standards, welfare and poverty of individuals or household.

The study is based on primary as well as secondary data. Primary data were collected from primary sources. The sources of primary data are obviously based on the information obtained from the head of the households. A household survey and group discussion techniques were used to obtain statistical data and required information.

The findings reveal that 28 percent of the total studied households are experiencing catastrophic health expenditure. 7 percent of the household are poor and 6 percent of the households fall below the poverty line because of the health expenditure. It was also found that the normalized poverty gap as 1.97 percent whiles the poverty gap after deduction of OOP is 2.65 percent (an increase by 0.68 percent). This indicates a percentage point change by 34.5 percent of the conventional poverty gap.
\end{abstract}

Key Words: Catastrophic, Impoverishment, Poverty, Expenditure, Health

\section{Introduction}

Health is a state of complete physical, mental and social well-being and not merely the absence of diseases or infirmity (WHO, 2006). The enjoyment of the highest attainable standard of health is one of the fundamental rights of every human being without distinction of race, religion, and political belief, wealth or social condition. The health of all people is fundamental to the attainment of peace and security and is dependent upon the fullest co-operation of individuals and states (WHO, 2006). The report of the Commission on Macroeconomics and Health convincingly

Teaching Assistantof Saraswati Multiple Campus (Humanities Faculty, Economics Department), Tribhuvan University, Nepal 
locates health at the heart of development and draws attention to the importance of investing in health to enable poor people to break out poverty.

Ill-health, due to infectious and chronic diseases, leads to suffering, disability and premature death, affecting social and economic development of a nation. The productivity of an individual depends greatly on his or her health status. Therefore improving the health status of a nation's population will contribute greatly towards achieving its development goal. The gap between the poor and the rich increases since it is the poor who suffer more ill-health than the rich.

Catastrophic health expenditure refers to health spending that forces households to reduce their basic consumption or sell assets or borrow or to cut the consumption of other goods to pay for health care to an extent that leads to impoverished. Based on the world health organization, catastrophic health expenditure occurs when a proportion of a household's health spending to the household's capacity to pay exceeds 40 percent of household's capacity to pay. Out-of -pocket payments for health care includes all categories of health elated expenses such as doctor's consultation fees, purchase of medicines, lab expenses, and hospital bills paid directly by the household at the time the household receives the health service.

Poverty alleviation remains a major challenge for Nepal. Although initiation has been taken to reduce poverty since the Ninth Plan (1996/97-2002/2003) by placing it at the centre of planned development endeavors and as the poverty ratio has reduced to 25.4 percent at the end of FY 2008/2009, poverty is still a major problem in Nepal. According to Nepal Living Standard Survey 2010/11, the poverty incidence for Nepal in 2010-2011 is 25.16 percent and the Gini-coefficient is 0.328 . The poverty rate is much lower in urban areas (15.46\%) than rural areas $(27.43 \%)$ (CBS, 2011).According to the latest estimates of the National Planning Commission, absolute poverty is estimated to be around 16.67 percent in the fiscal year 2019/20 and it was 18.7 percent in fiscal year 2017/18 (Economic Survey, 2019/20). It seems that the analysis of the poverty in Nepal does not account for the impact of health expenditure of the household although health expenditure can exacerbate poverty. Nepal has improved itself in Human Development Index (HDI). According to Human Development Report 2019, its HDI stands at 0.579 , which gives the country a rank of 158 out of 189 countries and life expectancy at birth is 69.1 years.

\section{Health System Structure in Nepal}

Nepal's health care system is hierarchically structured could be compared to four-layer pyramid: primary care at below district level, primary care at district level, secondary care and tertiary care, from bottom level to top level respectively. Ministry of Health and Population (MOHP), which operates a nationwide system of facilities and programs, provides largest capacity for health care services. The government health care system consists primarily of a network of hospitals and public health offices throughout the country. Public health care providers are heavily subsidized and dominate health care market; however, the private health care providers are playing important role in delivery of health particularly in urban area. Primary care at below district level includes sub-health post (SHP), health posts (HP) and primary health care centers (PHCC) provide clinical and preventive services at free of cost with good coverage of rural areas. Primary care at district level includes district hospitals and district public health offices. District hospital (DH) provides inpatient, emergency and outpatient services whereas the district public health offices are primarily responsible for providing preventive services. Secondary care is provided by zonal and 
sub regional hospitals with various degree of specialization in curative care. Finally, tertiary care is at the top level of health service pyramid that includes central hospitals, university teaching hospital and large private hospitals. Our attention in this study is district hospital services because DHs play a key role in providing outpatient, inpatient, and emergency services throughout the country at affordable prices, and serve as the referral point for primary health care below district level. Child health, maternal health communicable and non communicable diseases related services, pathology tests and diagnostic services, $\mathrm{x}$-ray services and among others are available at DHs. DH, therefore, is considered as backbone of curative services in Nepal (Adhikari, 2013)

\section{Health Financing System of Nepal}

Health financing is a major concern and issue in non-profit and non-government health sector reform and system development. Financing sources in Nepal can be classified by contribution mechanism as government, private (households and institutions) and 'rest of the world'. Rest of the world refers to financial support from foreign sources (to both the public and private sector). Out-of-pocket expenditure is the largest source of funding in Nepal, followed by government expenditure. The OOP payment method for health care should be reduced, as it is the most unfair/regressive way of funding health services. The second largest financing sources is public (government) funds and includes taxes, non-tax revenue and support from external development partners, and comes through different administrative levels. The contribution of external development partners is a substantial part of Nepal's total health expenditure (Torres et. al. 2011).

Nepal Total Health Expenditure (THE) was 159.71 billion which was 6.0 percent of GDP and the per capita THE was 543 in the year 2016/17(National Health Account - 2018). Within the total public health expenditure, MOHP (Ministry of Health and Population) and institutions under MOHP are predictably the dominant category sharing 76.1percent. The remaining 23.9 percent is shared by other ministries, government health facilities and local bodies. The major sources of finance for THE include the private sector, general government and rest of the world. Of these sources, the private sector remains the main source of health finance in Nepal, comprising 60.5 percent of THE in 2018/19 (National Health Accounts, 2016/2017-2018-2019). Additionally, Out of total private financing, OOP expenditure alone accounts for 90 percent of throughout the review period 2016/17 - 2018/19. Non-profit institutions remained the second largest source, contributing 6.2 percent of total private financing in 2018/19 and corporations' expenditures constitute roughly 3 percent of total private sector financing during same period (National Accounts, 2018).

The composition of total health expenditure is 44 percent public expenditure, with the remaining 56 percent coming from private sources. The GON share stands at 21 percent of the total health expenditure, For 2018/2019, while external partners contribute the remaining 18.9 percent of THE (National Health Accounts, 2018). The impact of out-of pocket payments for health care can become catastrophic over time and can significantly affect the living standards of individuals. Out-of-pocket spending on health care has become a policy concern for three reasons: First, households may be pushed into poverty or into deeper poverty as a result of paying directly for health services. Second, households facing these health expenses may cut back on other essential household spending such as food and clothing. Third, households may, in fact, choose to forgo necessary health care services rather than face the steep financial consequences - creating a vicious cycle of ill health, disability, and poverty. In the case of out of pocket payments, accessing 
health care services are dependent on the economic status of the individual or household. If the costs of the health care so high meeting demand of the health care is challenging and the households are unable to recuperate them from existing resources and hence ultimately slip deeper in to poverty (Mondal et. al. 2010). Households may borrow money ,sell assets or divert resources from other needs to seek health care, if the health care cost is unaffordable, so Out of pocket spending is regarded as the most unequal system of health financing and it is necessary to study regarding out of pocket payments for health care with reference to catastrophic and impoverishment. It is necessary to develop the mechanism to protect the households from catastrophic health expenditure but options are limited to mitigate such burden (Su et al .2006). As a result, it remains a challenge to protect the households from catastrophic health expenditure in the developing countries like Nepal where there is a high level of poverty.

\section{Objectives of the Study}

i) To identify determinants of the catastrophic health expenditure in the study area.

ii) To find the effect of out of pocket payments for health on poverty in the study area.

\section{Literature Review}

Adhikari, Maskey and Sharma (2009) studied to assess catastrophic, impoverishment and economic consequences of paying for hospital based care of Kala-azar in Nepal utilizing microdata on a random selection of 50 percent of the KA-affected households of Siraha and Saptari districts of Nepal and concluded that substantial costs for obtaining health care services, despite free services by public health institutions, push the low income households below poverty level. The empirical results suggest that direct costs of hospital-based treatment of KA are catastrophic since they consume 17 percent of annual household income. This expenditure causes more than 20 percent of KA-affected households to fall below the poverty line, with the remaining households being pushed into the category of marginal poor; the poverty gap ratio is more than 90 percent. Further, KA incidence can have prolonged and severe economic consequences for the household economy due to the mechanisms of informal sector financing to which households resort. A heavy burden of loan repayments can lead households on a downward spiral that eventually becomes a poverty trap. In other words, the method of financing health care payments is an important ingredient in understanding the economic burden of disease.

Pal (2010) catastrophic OOP health expenditure is concerned with high levels of OOP health expenditure which might affect household's standard of living. From the literature, catastrophic expenditure has been defined as that level of OOP health spending which exceeds some fixed proportion of household income or household's ability to pay.

Varadarajan, Moharaana and Venktesn (2013) studied 'Health care Expenditure of Rural Households in Pondicherry, India' with a sample of 100 households adopting the methodology described by Xu $\mathrm{k}$ et al. The study indicates that higher proportion of reported illness and the households belonging to higher median household expenditure are the determinants of catastrophic health expenditure. The major findings in the study are 60 percent of the sampled households incurred catastrophic health expenditure and 18 percent were impoverished by paying for health expenses. 
Rehman et al (2013) has studied about health related financial catastrophe, inequality and chronic illness in Bangladesh using the approach of $\mathrm{Xu}$ and colleagues. In the study, they have used double hurdle and Poisson regression models to identify the determinants of OOP payments and catastrophic expenditure respectively. According to the study, Economic status, chronic illness, household size, average illness per child and adult, care seeking behavior, education of household head and household consumption quintile are the determinants of OOP payments and catastrophic expenses. The findings indicated that nearly 9 percent of the households faced catastrophic health care and at a non-food expenditure threshold of 25 percent and 40 percent, the incidence of catastrophic expenditure were 9.8 percent and 17.6 percent respectively. The average number of illness, both per child and per adult increased the relative risk of incurring catastrophic payments by 1.12 times and 1.47 times for a single additional average illness in children and adults respectively.

\section{Research Methodology}

\section{Conceptual Framework}

A catastrophic payment is defined on a household capacity to pay (Xuet.al.2003). The estimation of a households' capacity needs data on total household expenditure and subsistence expenditure. To identify the determinants of catastrophic health expenditure, logit model has been used using catastrophic health expenditure as binary variable and other variables such as sex of the household head, residence of the household head, education status of the household head, employment status of the household head, health seeking behavior of the households, household size, number of children under five years old, number of household members suffering from chronic illness and other health problems have been used as independent variables.

Household

characteristics

- Demographic compositionof $\mathrm{HH}$

- $\mathrm{HH}$ size

- Education status

- Employment status

- Types of illness

\begin{tabular}{|l|l|l|}
\hline \multicolumn{2}{|c|}{ Outcome } & \multicolumn{1}{c|}{ Measurement } \\
\hline $\begin{array}{l}\text { Out-of-pocket } \\
\text { payment for } \\
\text { health } \\
\text { expenditure }\end{array}$ & $\begin{array}{l}\text { Catasrophic } \\
\text { health } \\
\text { expenditure }\end{array}$ & $\begin{array}{l}\% \text { of households } \\
\text { facing catastrophic } \\
\text { health expenditure }\end{array}$ \\
& $\begin{array}{l}\text { Poor, impoverishment } \\
\text { and poverty gap }\end{array}$ \\
\hline
\end{tabular}

- Health seeking behavior

- Placeof residence 


\section{Study Area}

Ratnanagar municipality as urban and Shaktikhor village as rural area of Chitwan district has been taken as the study area. These sites were selected because it has come to know that the people in these areas have experienced catastrophic health expenditure that can seriously compromise their living standard and the study area is characterized by diversity in income resources, occupation, utilization of health facilities, health expenditures etc.

\section{Study Design}

In this study, a cross sectional survey design was employed for collecting household level data on households' demographic composition, households' total income ,households' total expenditure, food expenditure, health related expenditure, education ,employment status of the households' heads, household size, illness, health seeking behavior and place of residence etc from 200 households. As the study was based on primary data, structured questionnaires were used to collect the necessary data. Selection of Ratnanagar and Shaktikhor as study area is purposive.

\section{Sources of Data}

The study is based on primary as well as secondary data. Primary data were collected from primary sources. The sources of primary data are obviously based on the information obtained from the head of the households. A household survey and Group discussion techniques were used to obtain statistical data and required information

\section{Model Specification for Data Analysis}

The model is adopted from WHO methodology to analyze the data.

\section{Impoverished health Expenditure Approach}

To apply the impoverished health expenditure approach, it is necessary to calculate the poverty line and the subsistence spending of households was used to determine the poverty line.

\section{Catastrophic Health expenditure Approach}

In order to use catastrophic health expenditures approach, it was necessary that the household financial contribution to health be calculated; so, it was generated as:

\section{Logit Model}

Drawing mainly from the WHO methodology (Xu et al., 2003a, 2003b) to assess catastrophic health payments and the extent of impoverishment that derives from such high out-of-pocket payments, this thesis tries to study the poverty impact of catastrophic health expenditure and determinants of catastrophic health expenditure.

In both rural and urban area of the study, the items under which data on expenditures were collected for comprised payments made for food, non-food (such as electricity, education, 
clothing, health care) and other goods and services by households to meet their daily needs. These were categorized into expenditures for food, non-food and health expenditure. The aggregate between the food and non-food was taken to represent total consumption expenditure. The out-ofpocket payments were payments made for medical products, appliances, services and for medical expenditure made during study period. The logistic regression technique was used to analyze the determinants of CHE using household survey data in Ratnanagar Municipality and Shaktikhor village. The dependant variable, CHE is a binary outcome defined as 1 when the household faces catastrophic health expenditures and 0 otherwise. The basic unit of analysis in this study was the household. Given that the dependant variable, CHE is a binary outcome, a latent variable with a dichotomous realization is specified and forms the basis for the use of logistic regression analysis. Logistic regression determines the impact of multiple independent variables presented simultaneously to predict membership of one or other of the two dependent variable categories. Logistic regression calculates the probability of success over the probability of failure; the results of the analysis are in the form of an odds ratio.

The Logistic regression also provides knowledge of the relationships and strengths among variables. The logistic regression modeling technique was based on the assumption that the error term follows a logistic distribution. The data in the present study follows logistic distribution as catastrophic health expenditure is a dichotomous dependent variable and there are independent variables; the relationship between dichotomous dependent variable and independent variable can be measured through logistic model. A logit regression model is used to investigate the determinants of catastrophic health expenditures.

$\mathrm{Y}=\beta_{0}+\beta_{1} \mathrm{X}_{1}+\beta_{2} \mathrm{X}_{2}+\beta_{3} \mathrm{X}_{3}+\ldots \ldots \ldots+\beta_{\mathrm{n}} \mathrm{X}_{\mathrm{n}}+\varepsilon$

The binary dependent variable (Y) equals one when a household encounters catastrophic health expenditure and zero otherwise.

\section{Analysis of Catastrophic Health Expenditure and its Poverty Impact}

The study present and discuss the empirical findings of the catastrophic health expenditure and its poverty impact. The study is based on Ratnanagar municipality and Shaktikhor village of Chitwan district. The number of households in the study area is 3177 . Out of these 3177 households, 200 households have been selected as a sample for the study. Total sample households consist of 1006 population. Hence average population of each household size is 5.03, which is greater than national average.

In this study, catastrophic health expenditure is measured on the basis of subsistence expenditure which is also a poverty line. The subsistence expenditure calculated from the collected household data for household with single member is Rs 37,219.According to catastrophic health expenditure approach, catastrophic health expenditure has been calculated on the basis of capacity to pay. The household who reports food expenditure lower than the subsistence expenditure, capacity to pay has been generated by subtracting food expenditure from gross household expenditure and for the household whose food expenditure is higher than the subsistence expenditure or equal to it, capacity to pay has been calculated by subtracting subsistence expenditure from gross household expenditure. The current study has applied the WHO method. The household is known as 
experiencing catastrophic health expenditure whose health expenditure is greater than or equal to 40 percent of capacity to pay. According to impoverishment health expenditure approach, a household is regarded as poor when its total household expenditure is smaller than its subsistence spending, otherwise, it is considered as comfortable. To measure the poor and impoverishment condition of the households because of the health expenditure, the researcher has applied the impoverishment health expenditure approach. Analysis of data shows the fact that about 28 percent of all the households in the study area experience catastrophic health expenditure .A household is regarded as poor when its total expenditure is smaller than its subsistence expenditure. On the basis of this, 7 percent of the people are regarded as poor.

Table1. Households with Catastrophic Health Expenditure

\begin{tabular}{|c|c|c|c|}
\hline & Frequency & Percent & Cumulative \\
\hline Otherwise & 144 & 72 & 72 \\
\hline Catastrophic & 56 & 28 & 100 \\
\hline Total & $\mathbf{2 0 0}$ & $\mathbf{1 0 0}$ & \multicolumn{2}{c|}{ Source: Field Survey 2018/19 }
\end{tabular}

Table 2.Impoverishment Impact of Health Expenditure

\begin{tabular}{|l|l|c|c|}
\hline \multirow{2}{*}{ Valid } & & Frequency & Percent \\
\cline { 2 - 4 } & Otherwise & 174 & 87.0 \\
\cline { 2 - 4 } & Impoverishment & 12 & 6.0 \\
\hline \multirow{2}{*}{ Total } & Poor & 14 & 7.0 \\
\hline \multicolumn{2}{|r|}{} & $\mathbf{2 0 0}$ & $\mathbf{1 0 0 . 0}$ \\
\hline
\end{tabular}

Health expenditure is a major cause for the poverty; it has pushed the population in the study area below poverty line and impoverished. Based on impoverishment health expenditure approach, table no. 2 shows that about 7 percent of the household are poor because of health expenditure. Similarly, the results of the study reveal that 6 percent of the households fell below the poverty line due to financial hardship of health expenditure. The estimated poverty line for a household composed of a single member equals Rs 37,219.79 in the study area. Table no. 2 depicts the current situation of poverty and impoverishment of the households in the study area because of the out of payment expenditure for health.

\section{Poverty Gap}

The study attempts to examine the impact of OOP for health on poverty gap. The normalized poverty gap is calculated before and after making OOP. The difference in the normalized poverty gap reflects the impact of OOP on poverty intensity.

Normalized poverty gap is calculated before OOP deduction as follows 
Normalized poverty gap $=\frac{1}{N} \sum_{h=1}^{H} \frac{G h}{S e h}$

Where $\mathrm{G}_{h}$ equal $\mathrm{s}_{\mathrm{eh}}$ less total expenditure for poor households; the gap equals Zero for non-poor households.

$\mathrm{G}_{h}=$ (seh- Total_exph).I (If seh>Total_exph)

Then the normalized poverty gap is recalculated after making OOP is as follows.

Normalized poverty gap $=1 \frac{1}{N} \sum_{h=1}^{H} \frac{P_{\text {ost_Gh }}}{\text { seh }}$

Where Post Gh equals seh less total household expenditure after making OOP for poor households including households that spend less than se $h$ after making OOP, Normalized poverty gap equals zero for non poor households.

Post_G $h=[\mathrm{se} h$-( Total_exp $h$-oop $h)]$. I [If $=[\operatorname{she}>($ Total_exp $h$-oop $h)]$

The result shows the normalized poverty gap as 1.97 percent while the poverty gap after deduction of OOP is 2.65 percent (an increase by 0.68 percent). This indicates a percentage point change by 34.5 percent of the conventional poverty gap.

\section{Determinants of Catastrophic Health Expenditure}

The logistic regression analysis was conducted to determine the variables that influence the CHE. Logistic analysis is used to examine the effect of an explanatory variable, keeping the effects of all other variables constant. The coefficients used in logistic regression are odd ratios that provide the odds in favor of or against a household experiencing a catastrophic health expenditure event. The model results show that several variables are associated with catastrophic health expenditure. Based on the results of the regression analysis, the major factors influencing the occurrence of catastrophic health expenditure are: place of residence, household size, no of household members with chronic illness, education status of the household heads, the households having children under five years old, health seeking behavior of the households.

The results of the study shows that the household heads who are uneducated were 3.15 times more likely to incur catastrophic health expenditures in comparison to the households which are headed by educated member. The results suggest that having children under five years old is a risk factor for catastrophic health expenditure. Having a child under five years old in this study also significantly increased the probability that a household incurred catastrophic health expenditure. In fact, households with the children under five years old were 2.3 times more likely to incur catastrophic health expenditure when compared to households with no children under five years old. Households having a member suffered from chronic illness were 2.382 times more likely to incur CHE in comparison to those households where no members suffered from a chronic illness.

Another variable which influenced the occurrence of CHE is health seeking behavior of the households. The results of this study showed that the households who went to the private health institutions for the consulting the health workers for their illness were 3.193 times more likely to incur catastrophic health expenditure compared to the households who went to the government 
health institutions .Similarly, the households who reside in rural areas were more likely to incur catastrophic health expenditure and large households are also more protected against the catastrophic health expenditure compared to small households. The reason is that large households take advantages of economies of scale of household consumption. In addition large households have more working members than small households. The results of the study also show that the following variables had no effect on the probability that a household incurs CHE.Sex of the household heads, Household having members with other health problems or injuries, Age of the household heads, Occupation status of the household heads

\section{Major Findings}

The findings of this study also showed that, the majority of policies that are targeted at financial risk protection of households, such as targeted exemptions of user fees, economic aid for those suffering from chronic illness etc, for the poor and the elderly fall short of expectations. The fact that this is the case suggests that either these policies are inadequate or are not being implemented. As a result, there is a critical need to review these policies. Besides, it is necessary to review the health policy of Nepal as there has been a paradigm shift in the trend of diseases and people now are suffering more from non-communicable diseases. The major findings of the present study are given below.

1. It was measured that 28 percent of the total studied households are experiencing catastrophic health expenditure. 7 percent of the household are poor and $6 \%$ of the households fall below the poverty line because of the health expenditure. It was also found that the normalized poverty gap as 1.97 percent whiles the poverty gap after deduction of OOP is 2.65 percent (an increase by 0.68 percent). This indicates a percentage point change by 34.5 percent of the conventional poverty gap.

2. Place of residence, household size, no. of household members suffering from chronic illness, education status of the household heads and household having children less than five years old are the major factors influencing the occurrence of the catastrophic health expenditure. About 28 percent households were found to incur the catastrophic health expenditure.

3. People in the study area have been poor because of the OOP payments for health care. They have been pushed below poverty level because of the catastrophic health expenditure. About 6 percent households fell below poverty line in the study area.

4. About 67 percent households are found to have the household members suffering from a chronic illness and about 88 percent households have the members suffering from any other health problems and injuries.

\section{Conclusion}

The study describes the field study on the catastrophic health expenditure and its impact on poverty in Ratnanagar municipality and shaktikhor village. The people in the study area are severely affected by health expenditure. The high level of catastrophic health expenditure can be seen in this study. Catastrophic health expenditure is experienced by all socio- economic groups but severe impoverishment impact is experienced by poor. There are various reasons for the impoverishment impact of catastrophic health expenditure on the households. Amongst these are 
the lacks of health insurance coverage, low levels of government funding and inadequate financial protection of the vulnerable households. At the same time, People are not interested to public health services which are affordable also seems to be playing a role in driving households into catastrophic and impoverishing health expenditures. Thus, there is a clear and urgent need to strengthen mechanisms that are aimed at protecting households from the economic burden of OOP payments within the study area. Such mechanisms would include in particular, provision of health insurance coverage, improved government commitment to health funding as well as improvement of services of public health institutions so that people visit there to consult for the illness. Catastrophic and impoverishing health expenditures are also a major concern amongst households of differing socio-economic status. The results of this study clearly showed that the proportion of households facing CHEs was similar across socio-economic quintiles, and that OOP payments acted as a physical access barrier for both poor and non-poor households. Furthermore both poor and non-poor households were forced to finance their OOP payments through strategies that jeopardize their future livelihoods. This confirms the extent to which households from all levels of wealth are struggling to cope with OOP payments. So whilst it may be more feasible under the current economic climate to strengthen financial protection of the poorest households and possibly of vulnerable populations such as the elderly, the ultimate goal should aim at providing all households financial protection through universal health coverage. Such a strategy would inevitably ensure that not only are poor households protected from CHEs, but non-poor households are also shielded from CHEs and impoverishment.

\section{Bibliography:}

Adhikari, SR. (2013). "Choices of health care financing schemes for resources poor country: An analysis of Nepal's experiences .HealthVol, 5, No.8, pp.1295-1302

Adhikari , S R. Maskey N M. ,\& Sharma BP.(2009). Paying for hospital based care of kala-azar in Nepal: Assessing catastrophic impoverishment and economic consequences. Health Policy Plan, 24(2),pp.129-39.

.CBS.(2011).National Population Census and Housing Census 2011. National Planning Commission Secretariat, Government of Nepal.

CBS.(2011).NepalLiving Standard Survey 2010/2011.Kathmandu :Central Bureau of Statistics

Ghimire K.B. (2016). “Analysis of Catastrophic Household Health Expenditures and its Poverty Impact”Unpublished M.Phil. Dissertation, CEDECON, Tribhuvan University.

GIZ. (2011). Review of government health financing system in Nepal: Analysis and Recommendations. Kathmandu: German International Cooperation, Health Sector Support Programme.

MOF. (2019).Economic Survey, Fiscal Year 2013/2014, Government of Nepal.

MOHP, New ERA, \& Macro International In.(2011). Nepal Demographic Health survey 2011.Ministry of health and Population, New ERA, and Macro International Inc, Kathmandu, Nepal.

MOHP. (2019). Budget Analysis 2019/2020.Ministry of Health and Population. Kathmandu. 
MOHP. (2018).Nepal National Health Account 2017-2018.Ministry of Health and Population, Kathmandu.

Mondal, S., Kanjilai, B., Peters, DH. ,\& Lucas, H.( 2010).Catastrophic out-of- pocket for health care an its impact on households: Experience from West Bengal, India. Future Health Systems Innovation for equity, www.futurehealthsystems.org

Pal, R. (2010). Analyzing catastrophic health expenditure in india: concepts, determinants and policy implications. Indira Gandhi Institute of Development Research, Mumbai.February 2010, WP-2010-001.

Rehman M M., Gilmour, S., Saito, E., Sultan, P.,\& Shibuya, K.(2013). Health related financial catastrophe, inequality and chronic illness in Bangladesh. PLOS one 8 (2) e56873. doi:10.1371/journal.pone.0056873.

Torres, LVI.,Gautam, G S., Fuerst, F. ,\&Adhikari, C M.(2011). Assessment of the government health financing system in Nepal: suggestions for reform. Deutschegesellschaft fur international zusammenarbeit (GIH) GMBH.Health Sector Support Program .Department of Health Services ,Teku, Kathmandu.

Vardarajan, P., Moharana, L.,\&Venkatesan, M. (2013). Health care expenditure of rural households in Pondicherry, India. International Journal of Medical Students ", Vol 1, Issue 2, page 74-79. 